University of Windsor

Scholarship at UWindsor

$1-2014$

\title{
Continent-wide Patterns of Divergence in Acoustic and Morphological Traits in the House Wren Species Complex
}

\author{
J. R. Sosa-López \\ Daniel J. Mennill \\ University of Windsor
}

Follow this and additional works at: https://scholar.uwindsor.ca/biologypub

Part of the Biology Commons

\section{Recommended Citation}

Sosa-López, J. R. and Mennill, Daniel J., "Continent-wide Patterns of Divergence in Acoustic and Morphological Traits in the House Wren Species Complex" (2014). Auk, 131, 1, 41-54.

https://scholar.uwindsor.ca/biologypub/1173

This Article is brought to you for free and open access by the Department of Biological Sciences at Scholarship at UWindsor. It has been accepted for inclusion in Biological Sciences Publications by an authorized administrator of Scholarship at UWindsor. For more information, please contact scholarship@uwindsor.ca. 


\section{Continent-wide patterns of divergence in acoustic and morphological traits in the House Wren species complex}

Author(s): J. Roberto Sosa-López and Daniel J. Mennill

Source: The Auk, 131(1):41-54.

Published By: The American Ornithologists' Union

https://doi.org/10.1642/AUK-13-161.1

URL: http://www.bioone.org/doi/full/10.1642/AUK-13-161.1

BioOne (www.bioone.org) is a nonprofit, online aggregation of core research in the biological, ecological, and environmental sciences. BioOne provides a sustainable online platform for over 170 journals and books published by nonprofit societies, associations, museums, institutions, and presses.

Your use of this PDF, the BioOne Web site, and all posted and associated content indicates your acceptance of BioOne's Terms of Use, available at www.bioone.org/page/terms of use.

Usage of BioOne content is strictly limited to personal, educational, and non-commercial use. Commercial inquiries or rights and permissions requests should be directed to the individual publisher as copyright holder. 


\title{
Continent-wide patterns of divergence in acoustic and morphological traits in the House Wren species complex
}

\author{
J. Roberto Sosa-López* and Daniel J. Mennill
}

Department of Biological Sciences, University of Windsor, Windsor, Ontario, Canada

* Corresponding author: jrobertososa@gmail.com

Received September 5, 2013; Accepted November 11, 2013; Published January 8, 2014

\begin{abstract}
Phenotypic traits are important for assessing differences between populations, especially in groups with poorly resolved taxonomy. One such group, the House Wren complex, presents extensive taxonomic controversy and is thought to comprise many independent evolutionary units. Although the songs and morphological features of House Wrens (Troglodytes aedon) show extensive variation, differences between populations have not been quantified. We assessed variation in acoustic and morphometric traits within this complex and compared patterns of variation with currently recognized subspecies boundaries. First, we compared songs and morphology among eight recognized subspecies (T. a. aedon, T. a. parkmanii, T. a. cahooni, T. a. brunneicollis, T. a. nitidus, T. a. musculus, T. a. beani, and T. a. rufescens), controlling for significant effects of latitude. Second, we used variation in male song, a trait with an important role in mate choice and male-male competition, to assess divergence among subspecies. We compared variation among subspecies to variation across seven currently recognized Troglodytes species (T. hiemalis, T. pacificus, T. tanneri, T. sissonii, T. cobbi, T. rufociliatus, and T. ochraceus). Our results, based on broad sampling of songs $(n=786)$ and morphological traits $(n=401)$ from 609 locations throughout the Americas, show that most of the subspecies examined diverge in song, morphology, or both. In addition, the acoustic differences between subspecies are similar to, and in some instances greater than, the divergence between pairs of currently recognized species. Our results suggest that at least four allopatric subspecies-T. a. nitidus, T. a. musculus, T. a. beani, and T. a. rufescens-are likely different species, and we identify many other vocally and morphologically differentiated subspecies that may, upon further detailed genetic analysis, result in new species.
\end{abstract}

Keywords: Acoustic variation, geographic variation, House Wren, latitudinal variation, morphological divergence, song divergence, species limits, Troglodytes, vocalization

\section{Patrones de divergencia a nivel continental en características acústicas y morfológicas en el complejo de especies de Troglodytes aedon}

\section{RESUMEN}

Las características fenotípicas son importantes para evaluar las diferencias entre poblaciones, especialmente en grupos para los cuales la taxonomía no está bien determinada. El complejo de Troglodytes aedon es uno de estos grupos, ya que su taxonomía es muy controvertida y se cree que consta de varias unidades evolutivas independientes. Aunque los cantos y las características morfológicas de Troglodytes aedon muestran gran variación, las diferencias entre poblaciones no han sido cuantificadas. En este studio, evaluamos la variación en características acústicas y morfológicas dentro del complejo, y comparamos patrones de variación con los límites que se reconocen actualmente entre subespecies. Primero, comparamos cantos y morfología entre ocho subespecies reconocidas de Troglodytes aedon (Troglodytes a. aedon, T. a. parkmanii, T. a. cahooni, T. a. brunneicollis, T. a. nitidus, T. a. musculus, T. a. beani, T. a. rufescens), controlando por los efectos de latitud. Segundo, usamos la variación en el canto del macho—una característica con un papel importante en la elección de parejas y competencia entre machos-para evaluar la divergencia entre subespecies de Troglodytes aedon. Comparamos variación entre subespecies con variación entre siete especies reconocidas de Troglodytes ( $T$. hiemalis, $T$. pacificus, T. tanneri, T. sissonii, T. cobbi, T. rufociliatus, T. ochraceus). Nuestros resultados, basados en un muestreo amplio de cantos $(n=786)$ y características morfológicas $(n=401)$ de 609 localidades a lo largo de las Américas, muestra que la mayoría de las subespecies examinadas divergen en canto, morfología, o los dos. Además, mostramos que las diferencias acústicas entre subespecies son similares $a$, o en algunos casos mayores que, la divergencia entre pares de especies reconocidas actualmente. Nuestro estudio sugiere que por lo menos cuatro subespecies alopátricas-T. a. nitidus, T. a. musculus, T. a. beani, y T. a. rufescens-probablemente son especies distintas, e identifica muchas otras subespecies que muestran diferenciación vocal y morfológica, lo cual podría resultar en nuevas especies tras análisis genéticos detallados.

Palabras clave: Variación acústica, variación geográfica, Troglodytes aedon, variación latidudinal, divergencia morfológica, divergencia en canto, límites de especies, Troglodytes, vocalización 


\section{INTRODUCTION}

Biologists are faced with the difficult task of estimating biological biodiversity. Current inferences of species diversity in many groups are likely underestimated (Wilson 2003). For instance, the number of avian lineages in the tropics is thought to be greater than is currently recognized (Milá et al. 2012). Furthermore, recent findings of new bird species (e.g., Lara et al. 2012, Seeholzer et al. 2012, Hosner et al. 2013), along with revisions to the taxonomic status of many other species (e.g., Chesser et al. 2012, 2013), clearly indicate that further research in this field is required (Brumfield 2012).

One of the principal challenges for biologists when assessing diversity is to draw boundaries between species. This challenge is overcome by documenting phenotypic and genetic variation of organisms across geographic regions (Nyaìri 2007). The use of informative traits is crucial for delimiting species boundaries. Avian acoustic signals are important because they play a direct role in mate choice, male-male competition, and species recognition in many taxa (Catchpole and Slater 2008, Wilkins et al. 2013), thereby acting as premating isolation barriers. It is not surprising, therefore, that research focusing on song as an important phenotype has produced significant insight into avian taxonomy (e.g., Toews and Irwin 2008, Alström et al. 2011, Campagna et al. 2012, Lara et al. 2012, Sosa-López et al. 2013).

With well-known historical taxonomic problems and a distribution that includes most parts of the Americas (Figure 1), the House Wren complex stands out as an ideal group for exploring vocal geographic variation and its taxonomic implications. The American Ornithologists' Union (AOU) currently recognizes 30 subspecies of House Wren (Troglodytes aedon) within this complex (AOU 1998); however, the number of subspecies varies among taxonomic authorities (e.g., Brewer 2001, NavarroSigüenza and Peterson 2004, Kroodsma and Brewer 2005, Clements et al. 2012, Gill and Donsker 2013). Several authorities agree that all subspecies can be clustered into five main groups on the basis of slight morphological and geographical differences (e.g., AOU 1998, Clements et al. 2012). (1) The "aedon group" includes two subspecies: T. a. aedon in southeastern Canada and the eastern United States, and T. a. parkmanii from southwestern Canada and the central and western United States to Baja California, Mexico. (2) The "brunneicollis group" includes three subspecies: T. a. cahooni from the mountains of southern Arizona south to central Mexico, T. a. brunneicollis in the mountains of northeastern Mexico, south of the Sierra Madre del Sur of Oaxaca, and T. a. nitidus in the mountains of Zempoaltepec, Oaxaca. (3) The "musculus group" includes 20 subspecies, populating most areas from central Mexico south to Tierra del Fuego, with some subspecies restricted to islands. (4) The "martinicensis group" includes six subspecies, each restricted to its own island in the Lesser Antilles: T. a. guadeloupensis in Guadeloupe, T. a. martinicensis in Martinique (probably extinct), T. $a$. mesoleucus in St. Lucia, T. a. musicus in St. Vincent and Grenada, and T. a. rufescens in Dominica. (5) The "beani group" includes only the subspecies $T$. a. beani and is restricted to Cozumel Island in the Yucatan Peninsula, Mexico. Some taxonomic authorities treat most of these groups as full species. For example, Howell and Webb (1995) recognize the brunneicollis group and the beani group as full species, and both Navarro-Sigüenza and Peterson (2004) and Kroodsma and Brewer (2005) recognize the aedon group, brunneicollis group, musculus group, and beani group as full species. Clearly, there is little agreement on whether the major groups within this complex should be considered different species.

A series of recent genetic studies suggests that the aedon group, brunneicollis group, and musculus group have independent evolutionary trajectories (Brumfield and Capparella 1996, Rice et al. 1999, Martínez Gómez et al. 2005; also see Mann et al. 2006, Campagna et al. 2012). For instance, Brumfield and Capparella (1996) provided genetic data suggesting three or more distinct lineagesthe aedon group, brunneicollis group, and musculus group-and placed the brunneicollis group and the aedon group in the same clade, with the musculus group as the sister taxon. Rice et al. (1999) and Martínez Gómez et al. (2005) also support three distinct lineages, but they placed the brunneicollis group as the sister taxon. These studies used different subspecies of the brunneicollis group in their analysis; Brumfield and Capparella (1996) used T. $a$. cahooni, whereas Rice et al. (1999) and Martínez Gómez et al. (2005) used T. a. nitidus. Interestingly, T. a. cahooni is thought to be sympatric with $T$. a. aedon in southern Arizona, while T. $a$. nitidus has an allopatric distribution, isolated in the mountains of Zempoaltepec, Oaxaca (Kroodsma and Brewer 2005). In another study, Campagna et al. (2012) suggested the existence of significant genetic differences within the aedon group, between $T$. a. aedon (eastern Canada) and T. a. parkmanii (western Canada), placing T. a. aedon and subspecies of the musculus group in the same clade, and T. a. parkmanii as the sister taxon. There is a lack of consensus on whether the five currently recognized groups represent independent lineages, obscuring the taxonomy of this species complex.

Groups of Troglodytes that are restricted to islands (i.e. the beani group and martinicensis group) have received less attention than their mainland counterparts. Several authors have suggested that the island taxa within this complex are likely to be distinct species, based on their isolated distribution and on morphological differences in size as well as color (Navarro-Sigüenza and Peterson 2004, 


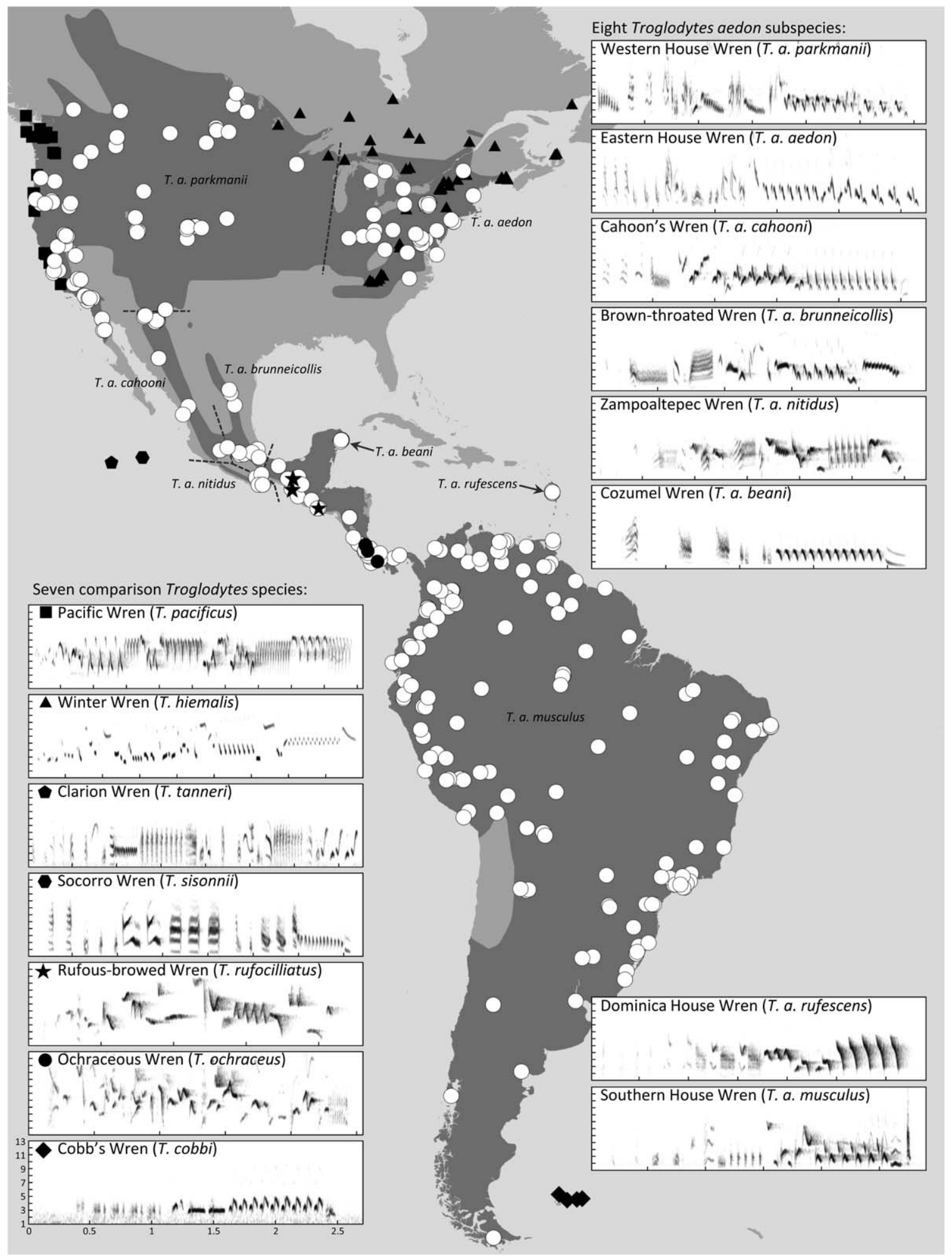

FIGURE 1. Map of North and South America, showing the recording locations for the songs of eight subspecies of Troglodytes aedon (open circles) and seven comparison species (filled symbols). The dark gray area shows the breeding-season distribution of $T$. aedon. Dashed lines indicate approximate boundaries between continental House Wren subspecies. Spectrograms at right depict one example of a male song from each of the eight subspecies analyzed. Spectrograms at left depict one example of a male song from each of the seven species that were analyzed for comparison. For all spectrograms, the $x$-axis tick marks show increments of $0.5 \mathrm{~s}$ (note that the time axis varies between spectrograms, to maximize display area), and y-axis tick marks show increments of $1 \mathrm{kHz}$ from $1 \mathrm{kHz}$ to $13 \mathrm{kHz}$. 
Kroodsma and Brewer 2005). Recent research on the Falkland Islands suggests that this is true for Cobb's Wrens (T. cobbi; Campagna et al. 2012, Chesser et al. 2013, Remsen et al. 2013).

Together, these previous investigations reveal complicated relationships within the House Wren complex and suggest the existence of several species, even within some of the five main groups. The vocalizations of House Wrens are known to exhibit substantial variation among these subspecies, but no study to date has empirically quantified the extent of bioacoustic variation (Johnson 1998). Similarly, morphometric variables are also suspected to vary in the House Wren complex, but no study has yet quantified this variation (Brewer 2001). A lack of behavioral and morphological data, and poor knowledge of genetic relationships, limits our ability to answer critical questions about the taxonomy of this group.

Here, we assess geographic variation in acoustic and morphological traits across subspecies in the House Wren complex. Our first objective was to assess whether differences in phenotypic traits correspond to recognized subspecies. Our motivation was to validate House Wren subspecific divisions using both fine-structural characteristics of male song and morphology. Our second objective was to understand the extent of song diversification among subspecies in the complex and provide a relative measure of song diversification to help improve the taxonomic classification of this group. To this end, we assessed the bioacoustic differences between subspecies of House Wrens that have an ambiguous taxonomic status and compared the magnitude of these differences to that seen between currently recognized Troglodytes species.

\section{METHODS}

Subspecies analyzed. We classified all recordings and morphological samples by subspecies using the taxonomy proposed by Kroodsma and Brewer (2005). We obtained acoustic recordings and morphological samples for eight subspecies: T. a. aedon, T. a. parkmanii, T. a. cahooni, T. a. brunneicollis, T. a. nitidus, T. a. musculus, T. a. beani, and T. a. rufescens. We pooled all our acoustic and morphological data corresponding to the musculus group under the category of T. a. musculus because we lacked data on subspecies boundaries within this South American group. We also pooled two possible subspecies recordings (but not morphological data) obtained from the Lesser Antilles into T. a. rufescens because we did not have information on the island where these recordings were collected (for recording details, see Supplemental Material Table S1). This lack of geographic resolution in the Lesser Antilles is not ideal, but we considered it important to include these recordings in our analysis because remarkably few recordings exist for these birds, and their taxonomic status is of great importance from a conservation perspective.

The distributions of some taxa within the complex are thought to overlap. For example, T. a. parkmanii and T. $a$. cahooni overlap in southern Arizona (AOU 1998, Kroodsma and Brewer 2005). For these groups, we used only recordings acquired during the breeding season, to avoid confusing northern migrants with resident southern birds. To further avoid any mismatch in subspecies identification, recordings made above 1,600 m elevation were considered to be from T. a. cahooni, whereas recordings made below this elevation were considered to be from T. a. parkmanii (Brewer 2001).

Acoustic analysis. Our sampling approach involved directly collecting recordings during field expeditions and gathering existing recordings from 16 natural-sound libraries and private collections (for details, see Supplemental Material Tables S1, S2). We collected recordings directly using three sets of equipment: a Marantz PMD660 digital recorder with a Sennheiser MHK67 shotgun microphone (recordings collected in WAV format; 44.1 $\mathrm{kHz}, 16$ bits); a Marantz PMD660 digital recorder with a Telinga parabola with a Sennheiser ME62/K6 omnidirectional microphone (recordings collected in WAV format; 44.1 kHz, 16 bits); or a Nagra Ares-BB + digital recorder with a Telinga parabola with a Stereo Pro 6 Telinga microphone (recordings collected in WAV format; $48 \mathrm{kHz}$, 16 bits).

We carefully scrutinized the recordings provided by libraries and private collections to prevent inclusion of more than one recording from the same individual. There were three instances in which we excluded recordings from our analysis: when multiple recordings clearly came from the same individual, when the identity of the bird in the recording was unclear and recordings were collected $<1 \mathrm{hr}$ apart, and when recordings were made on the same day but did not specify the recording time.

The recordings used in the analysis contained between 1 and 60 songs from the same individual. We randomly selected one song from each recording by generating a sequence of random numbers and matching the numbers with the number of the song in the recording. Each selected song was extracted and saved in a separate sound file with $\geq 0.5 \mathrm{~s}$ of silence at the beginning and the end. We created a spectrogram for every song using a 1,024-point fast Fourier transform, with $93.75 \%$ overlap, Blackman window, $22-\mathrm{Hz}$ frequency resolution, and 2.9-ms temporal resolution. We applied a $1-\mathrm{kHz}$ high-pass filter and measured all fine-structural characteristics of the songs using AviSoft-SASLab Pro version 5.2.04 (R. Sprecht, Berlin, Germany).

We conducted measurements using the "automatic parameter measurements" tool in Avisoft-SASLab Pro, thereby minimizing human subjectivity in collecting 
acoustic measurements. We detected the start and end of each element in the song by using a separation threshold of $-25 \mathrm{~dB}$ in relation to the maximum amplitude of the element; we distinguished separate elements when the amplitude dropped below the $-25 \mathrm{~dB}$ threshold for $\geq 5 \mathrm{~ms}$. Frequency variables were calculated using a threshold setting of $-20 \mathrm{~dB}$ in relation to the song's peak amplitude (see Supplemental Material Figures S1A, S1B), including all the peaks that exceeded the threshold. Measurements based on the power spectrum, such as entropy (see below), were derived from the average spectrum across an entire element. Songs of Troglodytes start with a series of lowamplitude introductory elements, and the threshold of automatic detection could not always detect these very quiet elements. In these cases, we selected the onset of the introductory section manually by looking at the first element on the spectrogram.

We quantified a total of 15 fine-structural features (depicted in Supplemental Material Figure S1). The first set of measurements was conducted at the level of the individual element. (1) Element length (s): the average duration of each element within the song. (2) Interelement interval (s): the average length of the silent space between elements, calculated as the average time from the end of the preceding element to the start of the current element for all the elements across the entire song. (3) Mean maximum frequency $(\mathrm{kHz})$ : the average maximum frequency of all elements within the song. (4) Mean bandwidth $(\mathrm{kHz})$ : the average bandwidth of every element within the song, calculated as the difference between the lowest (minimum) and the highest (maximum) frequency for each element. (5) Mean peak frequency $(\mathrm{kHz})$ : the average peak frequency of all elements within the song (peak frequency was determined as the frequency with the highest amplitude in the power spectrum for each element). (6) Mean entropy: the average entropy measurement for each element within the song. (Note that the entropy parameter is a measure of the randomness of the sound, with values ranging from 0 to 1 ; pure-tone elements have values close to 0 , and noisy sounds have values close to 1.) The second set of measurements was conducted at the level of the song. (7) Song length (s): the duration from the beginning of the first element to the end of the last element in the song. (8) Number of elements: total number of elements detected within the song. (9) Number of trills: We defined "trill" as a section of the song composed of a series of identical syllables repeated three or more times in a row (syllables can be composed of one or more elements, i.e. one or more continuous tracings on a sound spectrogram, as in Catchpole and Slater 2008). (10) Minimum frequency $(\mathrm{kHz})$ : the lowest frequency with amplitude delimited by the threshold from the power spectrum of each element, and across the entire song. (11) Maximum frequency $(\mathrm{kHz})$ : the highest frequency with amplitude delimited by the threshold from the power spectrum of each element, and across the entire song. (12) Peak frequency shifts per second: the number of times that the frequency peak switched between a value above and below $5.0 \mathrm{kHz}$, from one element to the next, sequentially across the entire song. We chose a threshold of $5.0 \mathrm{kHz}$ because this was the midpoint between the mean minimum and mean maximum frequencies; we counted the number of switches and divided them by the song length. This is similar to the variable "transitions per second" used by Toews and Irwin (2008) and Campagna et al. (2012). The third set of measurements was conducted to describe the variation in frequency and entropy between elements in a song. (13) Standard deviation (SD) in maximum frequency $(\mathrm{kHz}),(14) \mathrm{SD}$ in bandwidth $(\mathrm{kHz})$, and (15) SD in entropy.

Statistical analysis of acoustic data. To reduce the number of variables for analysis, and to avoid multicollinearity among variables in our analysis, we performed a principal component analysis (PCA), with varimax rotation, on the acoustic measurements outlined above. The analysis resulted in five principal component factors with eigenvalues $>1$ that together explained $74.8 \%$ of the total variation in the original 15 acoustic variables. The first factor was strongly associated with maximum frequency, SD in maximum frequency, SD in bandwidth, and SD in entropy; the second factor was strongly associated with mean maximum frequency, mean peak frequency, and peak frequency shifts per second; the third factor was strongly associated with song length, number of elements, and number of trills; the fourth factor was strongly associated with mean bandwidth and mean entropy; and the fifth factor was strongly associated with minimum frequency, element length, and inter-element interval (Table 1).

We then performed one-way analyses of covariance (ANCOVAs) to test whether subspecies differed from each other in the fine-structural characteristics of their songs (summarized by the five principal component factors), while controlling for variation in latitude (as a proxy for distance). In each analysis, we included one of the five principal component factors (Table 1) as the dependent variable. We used subspecies (i.e. T. a. aedon, T. a. parkmanii, T. a. cahooni, T. a. brunneicollis, T. a. nitidus, T. a. musculus, T. a. beani, or T. a. rufescens) as a fixed factor in the model, and latitude was entered as covariate. We then performed post hoc tests between pairs of subspecies using sequential Bonferroni-adjusted correction for multiple comparisons $(\alpha<0.05$; Holm 1979, Rice 1989). To improve normality, the second and fifth principal component factors were log transformed prior to analysis (Quinn and Keough 2002).

Morphological analysis. We gathered morphological data during field expeditions, and from specimens 
TABLE 1. Loadings of the first five principal component factors summarizing 15 acoustic variables measured from 573 individuals of different subspecies of Troglodytes aedon. Eigenvalues and the percentage of variation explained are presented for each component, and variables with the strongest loading are in bold.

\begin{tabular}{|c|c|c|c|c|c|}
\hline & Factor $1^{\mathrm{a}}$ & Factor $2^{a}$ & Factor $3^{a}$ & Factor $4^{a}$ & Factor $5^{a}$ \\
\hline Eigenvalues & 3.17 & 2.75 & 2.02 & 1.81 & 1.45 \\
\hline Variance explained (\%) & 21.10 & 18.30 & 13.50 & 12.10 & 9.60 \\
\hline \multicolumn{6}{|l|}{ Factor loadings } \\
\hline Element length (s) & -0.16 & 0.33 & 0.06 & -0.34 & 0.42 \\
\hline Inter-element interval (s) & 0.02 & -0.17 & -0.18 & -0.04 & 0.80 \\
\hline Mean maximum frequency $(\mathrm{kHz})$ & 0.28 & 0.82 & 0.03 & 0.42 & 0.03 \\
\hline Mean bandwidth $(\mathrm{kHz})$ & 0.30 & 0.35 & -0.03 & 0.77 & 0.23 \\
\hline Mean peak frequency $(\mathrm{kHz})$ & 0.12 & 0.90 & 0.07 & 0.07 & -0.04 \\
\hline Mean entropy & 0.18 & 0.14 & 0.03 & 0.83 & -0.13 \\
\hline Song length (s) & 0.12 & 0.13 & 0.79 & 0.09 & 0.39 \\
\hline Number of elements & 0.08 & 0.19 & 0.89 & -0.01 & -0.16 \\
\hline Number of trills & 0.02 & -0.07 & 0.72 & -0.05 & -0.18 \\
\hline Minimum frequency (kHz) & -0.05 & 0.42 & -0.06 & -0.33 & -0.53 \\
\hline Maximum frequency $(\mathrm{kHz})$ & 0.76 & 0.42 & 0.16 & 0.16 & -0.03 \\
\hline Peak frequency shifts per second & 0.11 & 0.74 & 0.12 & 0.10 & -0.20 \\
\hline $\mathrm{SD}$ in maximum frequency $(\mathrm{kHz})$ & 0.92 & 0.21 & 0.04 & 0.07 & 0.02 \\
\hline SD in bandwidth (kHz) & 0.91 & 0.08 & 0.02 & 0.24 & 0.13 \\
\hline SD in entropy & 0.81 & -0.08 & 0.07 & 0.12 & -0.12 \\
\hline
\end{tabular}

${ }^{a}$ Principal component analysis was based on the correlation matrix. Components with eigenvalues $>1$ were extracted. Factor scores were calculated using the regression method. The hypothesis that the correlation matrix contained only zero correlations was rejected (Bartlett's test: $\chi^{2}=6,066.9, \mathrm{df}=105, P<0.001$ ).

preserved in three museum collections: the American Museum of Natural History in New York, the Field Museum of Natural History in Chicago, and Museo de Zoología "Alfonso L. Herrera" in Mexico City (see Supplemental Material Tables S3, S4). Following Pyle (1997), we measured seven morphological characters: wing chord and tail length at $1 \mathrm{~mm}$ accuracy, and tarsus length, exposed culmen length, culmen length, bill depth, and bill width at $0.1 \mathrm{~mm}$ accuracy. We then applied the same series of statistical analyses that were used for the acoustic analysis. First, we reduced the number of variables using a PCA with varimax rotation. The analysis resulted in two principal component factors with eigenvalues $>1$ that together explained $68.2 \%$ of the total variation in the seven morphological variables. The first factor was strongly associated with tarsus length, exposed culmen length, culmen length, bill depth, and bill width; and the second factor was strongly associated with wing chord and tail length (Table 2).

We then performed one-way ANCOVAs to test whether subspecies differed from each other in morphological characters, while controlling for variation in latitude. In each analysis, we included one of the two principal components as the dependent variable (Table 2). We used subspecies (i.e. T. a. aedon, T. a. parkmanii, T. a. cahooni, T. a. brunneicollis, T. a. nitidus, T. a. musculus, T. a. beani, or T. a. rufescens) as fixed factor in the model, and latitude was entered as covariate. We then performed a post hoc test between pairs of subspecies using sequential Bonferroni correction for multiple comparisons.

For both the song and morphology ANCOVAs, residuals were normally distributed and all other assumptions were satisfied (Quinn and Keough 2002), except for homogeneity of regression slopes in the fifth acoustic factor and in the first morphological factor. The robustness of ANCOVA

TABLE 2. Loadings of the first two principal component factors summarizing seven morphological variables measured from 401 skins of different subspecies of Troglodytes aedon. Eigenvalues and the percentage of variation explained also are presented for each component. Factors with strong contributions to each principal component score are in bold.

\begin{tabular}{lrc}
\hline & Factor $1^{\mathrm{a}}$ & Factor $2^{\mathrm{a}}$ \\
\hline Eigenvalues & 3.40 & 1.37 \\
Variance explained (\%) & 48.60 & 19.60 \\
Factor loadings & & \\
Wing chord & 0.40 & $\mathbf{0 . 7 5}$ \\
Tail length & -0.24 & $\mathbf{0 . 8 1}$ \\
Tarsus length & $\mathbf{0 . 7 0}$ & 0.27 \\
Exposed culmen length & $\mathbf{0 . 8 6}$ & 0.12 \\
Culmen length & $\mathbf{0 . 8 6}$ & 0.11 \\
Bill depth & $\mathbf{0 . 7 6}$ & -0.11 \\
Bill width & $\mathbf{0 . 7 8}$ & -0.18 \\
\hline
\end{tabular}

\footnotetext{
a Principal component analysis was based on the correlation matrix. Components with eigenvalues $>1$ were extracted. Factor scores were calculated using the regression method. The hypothesis that the correlation matrix contained only zero correlations was rejected (Bartlett's test: $\chi^{2}=1,316.5, \mathrm{df}=21, P$ $<0.001)$.
} 
TABLE 3. Loadings of the first four principal component factors summarizing 15 acoustic variables measured from 786 Troglodytes songs, including subspecies of Troglodytes aedon and current recognized Troglodytes species. Eigenvalues and the percentage of variation explained also are presented for each component. Bold font indicates factors with strong contributions to each principal component score.

\begin{tabular}{|c|c|c|c|c|}
\hline & Factor $1^{a}$ & Factor $2^{a}$ & Factor $3^{a}$ & Factor $4^{a}$ \\
\hline Eigenvalues & 4.21 & 3.47 & 2.89 & 1.15 \\
\hline Variance explained (\%) & 28.10 & 23.10 & 19.20 & 7.70 \\
\hline \multicolumn{5}{|l|}{ Factor loadings } \\
\hline Element length (s) & 0.83 & -0.29 & 0.28 & 0.01 \\
\hline Inter-element interval (s) & -0.11 & -0.04 & -0.18 & 0.88 \\
\hline Mean maximum frequency $(\mathrm{kHz})$ & 0.04 & 0.24 & 0.94 & 0.05 \\
\hline Mean bandwidth $(\mathrm{kHz})$ & -0.60 & 0.48 & 0.32 & 0.31 \\
\hline Mean peak frequency $(\mathrm{kHz})$ & 0.38 & -0.06 & 0.84 & -0.09 \\
\hline Mean entropy & -0.63 & 0.43 & 0.16 & 0.17 \\
\hline Song length (s) & 0.87 & -0.11 & 0.29 & 0.15 \\
\hline Number of elements & 0.87 & -0.11 & 0.29 & -0.11 \\
\hline Number of trills & 0.75 & 0.03 & 0.04 & -0.14 \\
\hline Minimum frequency (kHz) & 0.55 & -0.26 & 0.33 & -0.32 \\
\hline Maximum frequency $(\mathrm{kHz})$ & 0.03 & 0.77 & 0.44 & -0.09 \\
\hline Peak frequency shifts per second & 0.16 & 0.04 & 0.70 & -0.34 \\
\hline SD in maximum frequency $(\mathrm{kHz})$ & -0.08 & 0.91 & 0.09 & -0.04 \\
\hline $\mathrm{SD}$ in bandwidth $(\mathrm{kHz})$ & -0.32 & 0.89 & 0.00 & 0.11 \\
\hline SD in entropy & -0.23 & 0.80 & -0.17 & -0.02 \\
\hline
\end{tabular}

a Principal component analysis was based on the correlation matrix. Components with eigenvalues $>1$ were extracted. Factor scores were calculated using the regression method. The hypothesis that the correlation matrix contained only zero correlations was rejected (Bartlett's test: $\chi^{2}=12,329.8, \mathrm{df}=105, P<0.001$ ).

to deviation of homogeneity of regression slopes increases with sample size (Hamilton 1976), and owing to our large sample size, we consider our analysis robust to the violation of this assumption for these two factors.

Acoustic divergence. We performed an additional PCA on all acoustic measurements, this time including the same eight House Wren subspecies in our original analysis, but adding measurements of the songs of seven recognized species: Cobb's Wren (T. cobbi), Clarion Wren (T. tanneri), Socorro Wren (T. sisonnii), Rufous-browed Wren ( $T$. rufocilliatus), Ochraceous Wren (T. ochraceus), Winter Wren (T. hiemalis), and Pacific Wren (T. pacificus). The analysis resulted in four principal component factors with eigenvalues $>1$ that together explained $78.5 \%$ of the total variation in the original 15 acoustic variables. The first factor was strongly associated with song length, minimum frequency, element length, number of elements, number of trills, mean bandwidth, and mean entropy; the second factor was strongly associated with maximum frequency, $\mathrm{SD}$ in maximum frequency, SD in bandwidth, and SD in entropy; the third factor was strongly associated with mean maximum frequency, mean peak frequency, and peak frequency shifts per second; and the fourth factor was strongly associated with inter-element interval (Table 3).

We calculated acoustic divergence scores as the pairwise distance between principal component factors for different wren taxa. To account for both the distance between group means as well as within-group variance, we used Cohen's $d$ scores in this analysis, providing a more accurate estimate of divergence (Toews and Irwin 2008). We calculated Cohen's $d$ as the difference between the two groups' mean principal component factor scores divided by the pooled SD (Cohen 1992). We calculated these acoustic divergence scores between each of the eight House Wren subspecies and all other House Wren subspecies (e.g., T. a. aedon vs. all other House Wren subspecies pooled). For comparison, we also calculated acoustic divergence scores between pairs of recognized Troglodytes species (e.g., T. sissonii vs. T. tanneri), selecting pairs of species that are known to be closely related: T. ochraceus vs. T. rufocilliatus (Martínez Gómez et al. 2005); T. pacificus vs. T. hiemalis (Toews and Irwin 2008); T. cobbi vs. T. musculus (Campagna et al. 2012); and T. sissonii vs. T. tanneri (two species restricted to adjacent islands off Mexico's Baja coast). We conducted this comparison for each of the four principal component factors that summarize variation in acoustic features. All statistical analyses used PASW Statistics version 18.0 (Chicago, Illinois, USA).

\section{RESULTS}

We measured geographic variation in the songs and morphology of House Wrens across 609 sites that comprised most of the geographic distribution of this species complex in North and South America. We gathered a total of 1,065 recordings from different sources and selected 786 recordings for analysis from different individuals (Figure 1; Supplemental Material Tables S1, 
TABLE 4. Summary of ANCOVA results for differences between subspecies of Troglodytes aedon in both acoustic ( $n=573)$ and morphological $(n=401)$ traits, using latitude as a covariate.

\begin{tabular}{|c|c|c|c|c|c|c|}
\hline Dependent variables & Model & $F$ & df & $P$ & $\eta^{2}$ & $R^{2}$ adj \\
\hline \multicolumn{7}{|l|}{ Acoustic analysis } \\
\hline \multirow[t]{3}{*}{ Factor 1} & Overall model & 4.6 & 8 & $<0.001$ & 0.06 & \multirow[t]{3}{*}{0.04} \\
\hline & Subspecies & 4.8 & 7 & $<0.001$ & 0.05 & \\
\hline & Latitude & 0.7 & 1 & 0.3 & 0.001 & \\
\hline \multirow[t]{3}{*}{ Factor 2} & Overall model & 55.9 & 8 & $<0.001$ & 0.4 & \multirow[t]{3}{*}{0.43} \\
\hline & Subspecies & 35.9 & 7 & $<0.001$ & 0.3 & \\
\hline & Latitude & 0.3 & 1 & 0.5 & 0.001 & \\
\hline \multirow[t]{3}{*}{ Factor 3} & Overall model & 16.7 & 8 & $<0.001$ & 0.1 & \multirow[t]{3}{*}{0.18} \\
\hline & Subspecies & 11.6 & 7 & $<0.001$ & 0.1 & \\
\hline & Latitude & 8.7 & 1 & 0.003 & 0.01 & \\
\hline \multirow[t]{3}{*}{ Factor 4} & Overall model & 5.0 & 8 & $<0.001$ & 0.07 & \multirow[t]{3}{*}{0.05} \\
\hline & Subspecies & 6.1 & 7 & $<0.001$ & 0.07 & \\
\hline & Latitude & 0.005 & 1 & 0.9 & $<0.001$ & \\
\hline \multirow[t]{3}{*}{ Factor 5} & Overall model & 30.8 & 8 & $<0.001$ & 0.3 & \multirow[t]{3}{*}{0.29} \\
\hline & Subspecies & 30.8 & 7 & $<0.001$ & 0.2 & \\
\hline & Latitude & 31.1 & 1 & $<0.001$ & 0.05 & \\
\hline \multicolumn{7}{|l|}{ Morphological analysis } \\
\hline \multirow[t]{3}{*}{ Factor 1} & Overall model & 69.5 & 8 & $<0.001$ & 0.5 & \multirow[t]{3}{*}{0.57} \\
\hline & Subspecies & 76.4 & 7 & $<0.001$ & 0.5 & \\
\hline & Latitude & 182.3 & 1 & $<0.001$ & 0.3 & \\
\hline \multirow[t]{3}{*}{ Factor 2} & Overall model & 16.4 & 8 & $<0.001$ & 0.2 & \multirow[t]{3}{*}{0.23} \\
\hline & Subspecies & 10.8 & 7 & $<0.001$ & 0.1 & \\
\hline & Latitude & 112.3 & 1 & $<0.001$ & 0.2 & \\
\hline
\end{tabular}

S2). Of the 786 recordings, 573 correspond to recordings of eight subspecies within the House Wren complex included in the present study: T. a. aedon $(n=54), T$. $a$. parkmanii $(n=103)$, T. a. cahooni $(n=45)$, T. $a$. brunneicollis $(n=14), T$. a. nitidus $(n=24)$, T. a. musculus ( $n=281), T$. a. beani $(n=40)$, and T. a. rufescens $(n=12)$. The remaining 213 recordings correspond to the seven recognized species in the House Wren complex that are included here: T. cobbi $(n=12), T$. rufocilliatus $(n=26), T$. sissonii $(n=30), T$. tanneri $(n=41), T$. ochraceus $(n=3), T$. hiemalis $(n=65)$, and T. pacificus $(n=36)$.

For the morphological analysis, we gathered morphometric data from 401 Troglodytes skins, all from adult male specimens, corresponding to $T$. a. aedon $(n=19), T$. a. beani $(n=12), T$. a. brunneicollis $(n=10), T$. a. cahooni $(n$ $=32)$, T. a. musculus $(n=279)$, T. a. nitidus $(n=11)$, T. a. parkmanii $(n=29)$, and $T$. a. rufescens $(n=9)$ (Supplemental Material Tables S3, S4).

Song analysis. Song differed significantly among the currently recognized subspecies in all five principal component factors (Table 4). Descriptively, we found that both T. a. parkmanii, in the United States and Canada, and T. a. beani, on Cozumel Island, have songs with higher scores for the first principal component factor, related to higher maximum frequencies, and larger variation in maximum frequencies, bandwidth, and entropy (Figure 2). North American subspecies (T. a. aedon, T. a.parkmanii, T. a. cahooni, T. a. brunneicollis, and T. a. nitidus) and T. a. rufescens, in Dominica, have songs with higher scores for the second principal component factor, related to higher mean maximum and peak frequencies, and higher numbers of shifts in peak frequency (Figure 2A). Troglodytes a. aedon, in the United States and Canada, and T. a. rufescens, in Dominica, have songs with higher scores for the third principal component factor, related to longer song lengths and higher numbers of elements and trills (Figure 2B). Troglodytes a. rufescens, in Dominica, has songs with higher scores for the fourth principal component factor, related to higher mean bandwidth and mean entropy (Figure 2C). T. a. brunneicollis and T. a. nitidus, in Mexico, T. a. musculus, in South America, T. a. beani, in Cozumel Island, and T. a. rufescens, in Dominica, have songs with highest scores for the fifth principal component factor, related to longer element duration and interelement interval, and lower minimum frequencies (Figure 2D).

Variation in two of five acoustic principal component factors had a significant association with latitude (Table 4). Values of the third factor, related to song length and number of elements and trills, decreased significantly with latitude, from north to south (Figure 3A). Values of the fifth factor, related to element duration, inter-element interval, and minimum frequency, increased significantly with latitude, reaching the highest values in Central America and then decreasing toward South America (Figure 3B).

Post hoc tests between subspecies following the ANCOVA on acoustic traits showed that T. a. aedon, $T$. 

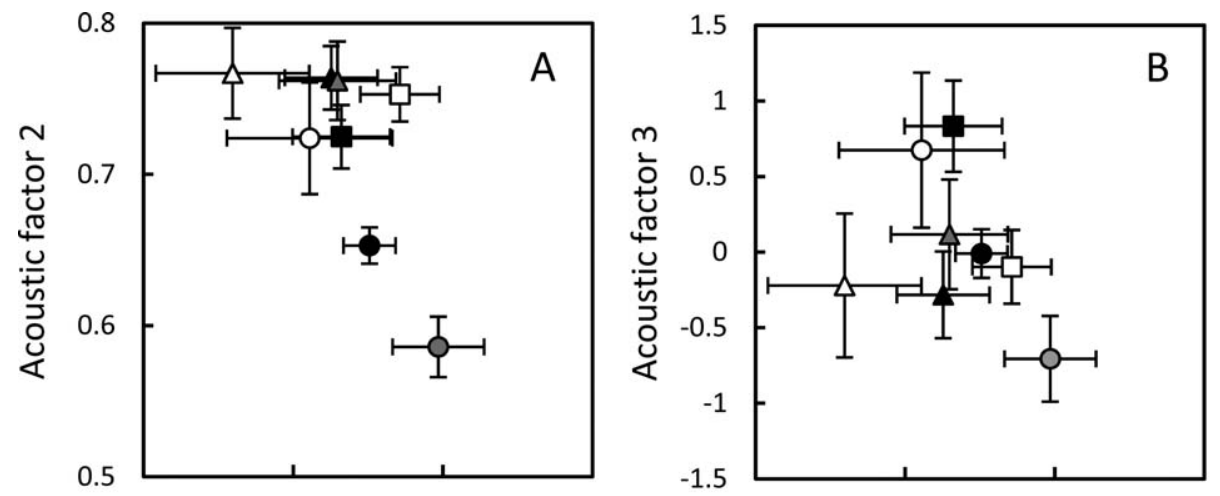

\author{
- T. a. aedon \\ 口T. a. parkmanii \\ $\Delta$ T. a. cahonii \\ $\Delta T$. a. brunneicollis \\ $\Delta T$. a. nitidus \\ - T. a. musculus \\ O T. a. beani \\ OT. a. rufescens
}
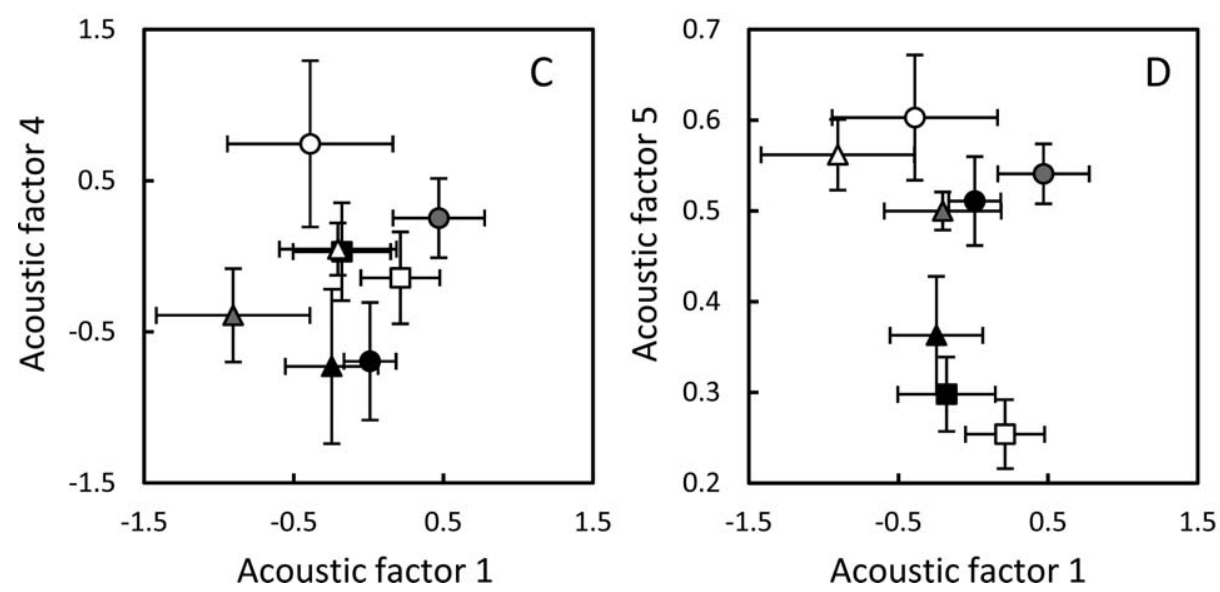

FIGURE 2. Acoustic variation between subspecies of Troglodytes aedon described by principal component factors that summarize variation in acoustic features of male songs. The first principal component factor is plotted against the second (A), third (B), fourth (C), and fifth (D). Points correspond to adjusted means after controlling for latitude. Bars indicate $95 \%$ confidence intervals.

a. parkmanii, T. a. cahooni, T. a. beani, T. a. musculus, and T. a. rufescens were significantly different from each other and from all other subspecies, whereas differences in song between T. a. nitidus and T. a. brunneicollis were nonsignificant (Table 5).

Morphological analysis. Morphological traits differed significantly between subspecies for the two principal component factors (Table 4). Descriptively, we found that T. a. beani, from Cozumel Island, has higher scores for the first principal component factor, related to longer tarsus length and beak characteristics, than other subspecies (Figure 4). North American subspecies (T. a. aedon, T. a. parkmanii, T. a. cahooni, T. a. brunneicollis, and T. a. nitidus) and T. a. beani, from Cozumel Island, have higher scores for the second principal component factor, related to longer wings and tails, compared to T. a. musculus and T. a. rufescens (Figure 4).

Variation in both morphological principal component factors showed a significant association with latitude (Table 4). Values of the first factor, related to tarsus length and beak morphology, increased significantly with latitude, reaching the highest values in Central America and then decreasing toward South America (Figure 3C). Values of the second factor, related to wing and tail size, decreased significantly with latitude from north to south (Figure 3D).

The post hoc tests following the ANCOVA on morphological traits showed that $T$. a. parkmanii and $T$. a. beani were significantly different from each other and all other subspecies in all pairwise comparisons, whereas morphological differences between T. a. aedon and T. $a$. cahooni, T. a. aedon and T. a. brunneicollis, T. a. cahooni and T. a. brunneicollis, T. a. nitidus and T. a. musculus, T. a. nitidus and T. a. rufescens, and T. a. musculus and T. a. rufescens were significant for some comparisons and nonsignificant for others (Table 5).

Acoustic divergence. Average divergence scores between the songs of each subspecies and all other subspecies of House Wrens were substantial. We calculated an acoustic divergence score of 0.4 for factor 1 (range: $0.2-$ 0.6 ); 0.5 for factor 2 (range: $0.3-1.0$ ); 0.9 for factor 3 (range: 0.6-2.2); and 1.1 for factor 4 (range: 0.7-1.4) (Figure 5). Average divergence scores between pairs of closely related species were similar for factor 1 (0.4, range: 0.2-0.7), factor 2 (0.6, range: $0.1-1.1)$, factor 3 (1.9, range: $1.2-2.9)$, and factor 4 (0.5, range: $0.2-1.1)$, based on pairwise comparisons of T. cobbi vs. T. a. musculus, T. tanneri vs. T. sissonii, 

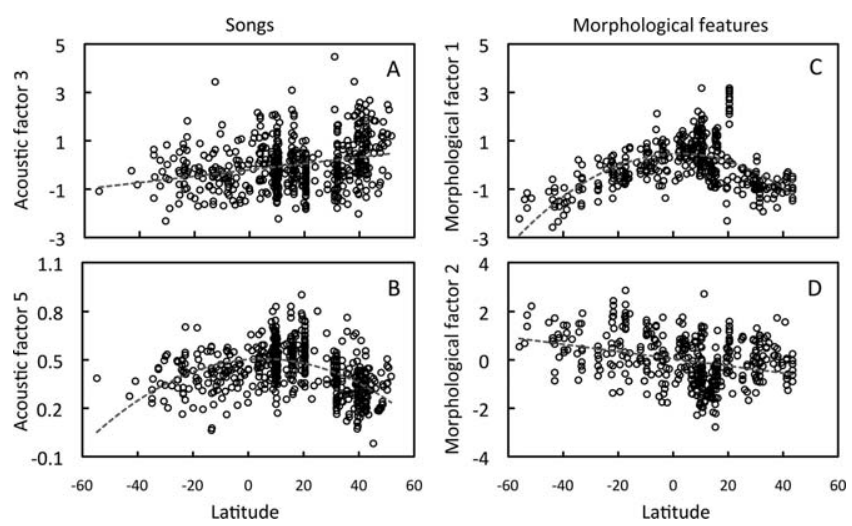

FIGURE 3. Songs and morphological features vary with latitude in subspecies of Troglodytes aedon. (A) Values of the third acoustic principal component factor, summarizing variation in song length, number of elements, and number of trills, decreases from north to south (linear regression: adjusted $R^{2}=$ $0.07, F_{1,567}=46.5, P<0.001$ ). (B) Values of the fifth acoustic principal component factor, summarizing variation in element length, inter-element interval, and minimum frequency (cubic regression: adjusted $R^{2}=0.2, F_{3,556}=68.8, P<0.001$ ). (C) Values of the first morphological principal component factor, summarizing variation in tarsus length, exposed culmen length, culmen length, bill depth, and bill width (cubic regression: adjusted $R^{2}=$ $0.3, F_{3,397}=83.5, P<0.001$ ), follow a similar pattern, with an increase in values from north to south, reaching the maximum values in Central America and then decreasing toward South America. (D) Values of the first morphological principal component factor, summarizing wing chord and tail length, decrease from north to south (linear regression: adjusted $R^{2}=$ $\left.0.1, F_{1,399}=47.7, P<0.001\right)$.

T. ochraseus vs. T. rufocilliatus, and T. hiemalis vs. T. pacificus. Our results suggest that acoustic divergence between pairs of subspecies of House Wrens was on the same order as acoustic divergence between recognized species for factor 1 (summarizing variation in element length, mean bandwidth, mean entropy, song length, number of elements and trills, and minimum frequency), factor 2 (summarizing variation in maximum frequency, variation in maximum frequency, variation bandwidth, and variation in entropy), and factor 4 (summarizing variation in inter-element interval). By contrast, divergence within subspecies was less pronounced for factor 3 (summarizing variation in mean maximum frequency, mean peak frequency, and peak frequency shifts per second) in our subspecies-level comparisons than in species-level comparisons (Figure 5; for full Cohen's $d$ values for effect sizes of acoustic divergence, see Supplemental Material Table S5).

\section{DISCUSSION}

On the basis of acoustic data from 768 individuals from 373 locations throughout the Western Hemisphere, as well as morphological data from 401 individuals from 236 locations, we quantified acoustic and morphological variation among subspecies of the House Wren complex. Our results reveal marked differences between all subspecies of House Wrens after controlling for latitude (as a proxy for distance), showing that it is possible to distinguish between them using acoustic traits, morphological traits, or both. Our acoustic analysis showed that vocal divergence between many subspecies was comparable to, or stronger than, the vocal divergence between pairs of currently recognized Troglodytes species. Together, these results suggest that at least four allopatric subspecies-T. $a$. nitidus ("Zempoaltepec Wrens"), T. a. musculus ("Southern House Wrens"), T. a. beani ("Cozumel Wrens"), and T. a. rufescens ("Dominica House Wrens")-may merit species status. In addition, our results shed light into the patterns of acoustic and morphological variation within the House Wren complex and have important implications for the taxonomy of this complex.

We found that most of the pairs of allopatric subspecies included in our analysis (e.g., T. a. aedon and T. a. beani) have distinctive features to their songs. Divergent acoustic traits in allopatric populations have been reported to occur in many other bird species, with isolation as the most parsimonious explanation for this pattern (e.g., VázquezMiranda et al. 2009, González et al. 2011, Campagna et al. 2012, Aleixandre et al. 2013, Sosa-López et al. 2013). For example, Cobb's Wrens (a close relative of House Wrens restricted to the Falkland Islands) are acoustically and genetically different from their continental counterparts (i.e. T. a. musculus; Campagna et al. 2012), as well as being morphologically different (Woods 1993). Moreover, experimental studies using playback have confirmed that divergent acoustic signals elicit different behavioral reactions in allopatric populations (e.g., de Kort and ten Cate 2001, Kirschel et al. 2009, Danner et al. 2011), supporting the idea that songs play a role in reproductive isolation.

Our morphological analysis shows that, despite general similarities, there are also significant differences between most pairs of allopatric subspecies (e.g., T. a. nitidus and T. a. beani). The general tendency of latitudinal increase in body size combined with a decrease in beak size in some subspecies of House Wrens (lowland subspecies T. $a$. aedon and T. a. parkmanii, vs. highland subspecies T. $a$. cahooni, T. a. brunneicollis, and T. a. nitidus; Figure 3) suggests that selection may drive morphological divergence along latitudinal gradients (McCormack and Smith 2008, Milá et al. 2010). Conversely, large beaks, such as those observed in T. a. beani on Cozumel Island, may be the result of relaxed competition for resources (Scott et al. 2003), a factor thought to drive divergence in beak size in island bird species (Boag and Grant 1984, Aleixandre et al. 2013). Other factors, such as drift, however, are also known 
TABLE 5. Results of post hoc pairwise comparisons of divergence between subspecies of Troglodytes aedon. Pairs of subspecies were compared for both acoustic and morphological divergence, and the principal component factors that showed significant differences following sequential Bonferrioni correction are shown.

\begin{tabular}{|c|c|c|c|c|}
\hline Subspecies & Acoustic differences? & Morphological differences? & Acoustic factors & Morphological factors \\
\hline \multicolumn{5}{|l|}{ Sympatric pairs of taxa } \\
\hline T. a. aedon vs. T. a. parkmanii & Yes & Yes & Factor 3 & Factors 1, 2 \\
\hline T. a. parkmanii vs. T. a. cahooni & Yes & Yes & Factors 4, 5 & Factor 1 \\
\hline T. a. cahooni vs. T. a. brunneicollis & Yes & No & Factor 5 & \\
\hline \multicolumn{5}{|l|}{ Allopatric pairs of taxa } \\
\hline T. a. aedon vs. T. a. cahooni & Yes & No & Factor 3 & \\
\hline T. a. aedon vs. T. a. brunneicollis & Yes & No & Factor 5 & \\
\hline T. a. aedon vs. T. a. nitidus & Yes & Yes & Factor 5 & Factor 1 \\
\hline T. a. aedon vs. T. a. musculus & Yes & Yes & Factors $2,3,5$ & Factor 1 \\
\hline T. a. aedon vs. T. a. beani & Yes & Yes & Factors $2,3,5$ & Factor 1 \\
\hline T. a. aedon vs. T. a. rufescens & Yes & Yes & Factor 5 & Factor 1 \\
\hline T. a. parkmanii vs. T. a. brunneicollis & Yes & Yes & Factors $1,4,5$ & Factor 1 \\
\hline T. a. parkmanii vs. T. a. nitidus & Yes & Yes & Factors 4,5 & Factors 1, 2 \\
\hline T. a. parkmanii vs. T. a. musculus & Yes & Yes & Factors 2, 5 & Factors 1, 2 \\
\hline T. a. parkmanii vs. T. a. beani & Yes & Yes & Factors $2,3,5$ & Factor 1 \\
\hline T. a. parkmanii vs. T. a. rufescens & Yes & Yes & Factor 5 & Factors 1, 2 \\
\hline T. a. cahooni vs. T. a. nitidus & Yes & Yes & Factor 5 & Factor 1 \\
\hline T. a. cahooni vs. T. a. musculus & Yes & Yes & Factor 2, 5 & Factors 1, 2 \\
\hline T. a. cahooni vs. T. a. beani & Yes & Yes & Factors $1,2,5$ & Factor 1 \\
\hline T. a. cahooni vs. T. a. rufescens & Yes & Yes & Factors $3,4,5$ & Factors 1, 2 \\
\hline T. a. brunneicollis vs. T. a. nitidus & No & Yes & & Factor 1 \\
\hline T. a. brunneicollis vs. T. a. musculus & Yes & Yes & Factors 1, 2 & Factor 1 \\
\hline T. a. brunneicollis vs. T. a. beani & Yes & Yes & Factors $1,2,3$ & Factor 1 \\
\hline T. a. brunneicollis vs. T. a. rufescens & Yes & Yes & Factor 4 & Factor 1 \\
\hline T. a. nitidus vs. T. a. musculus & Yes & No & Factors 2,4 & \\
\hline T. a. nitidus vs. T. a. beani & Yes & Yes & Factors 2,3 & Factors 1, 2 \\
\hline T. a. nitidus vs. T. a. rufescens & Yes & No & Factor 4 & \\
\hline T. a. musculus vs. T. a. beani & Yes & Yes & Factors 2, 3 & Factor 1 \\
\hline T. a. musculus vs. T. a. rufescens & Yes & No & Factor 2 & \\
\hline T. a. beani vs. T. a. rufescens & Yes & Yes & Factors 2, 3 & Factors 1, 2 \\
\hline
\end{tabular}

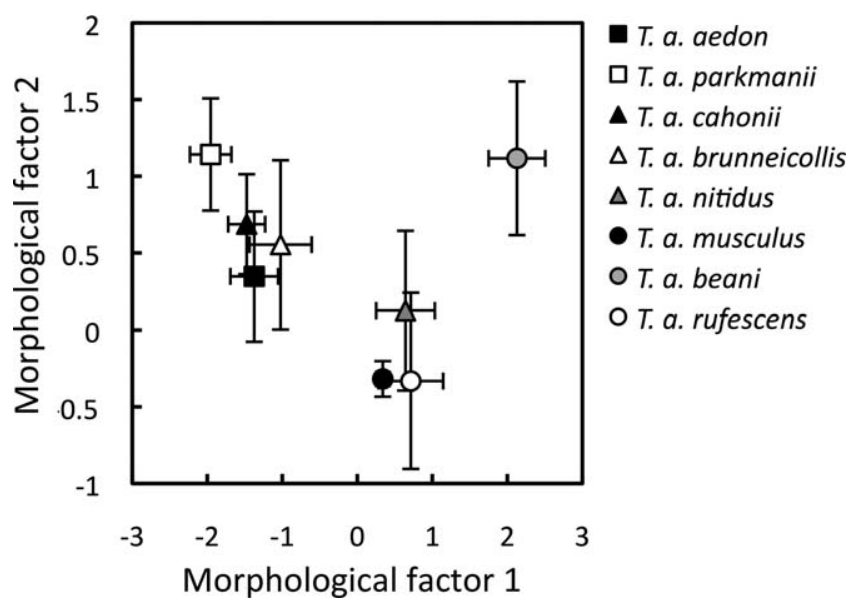

FIGURE 4. Morphological variation between subspecies of Troglodytes aedon described by principal component factors summarizing variation in morphological traits between the first two component factors. Points correspond to adjusted means after controlling for latitude. Bars indicate 95\% confidence intervals. to be related to divergence in morphological traits; future comparative studies can provide further insight into whether these factors are involved in morphological trait evolution in House Wrens.

Our results suggest that the subspecies of House Wrens with overlapping or abutting distributions have different songs (i.e. T. a. aedon vs. T. a. parkmanii, T. a. parkmanii vs. T. a. cahooni, and T. a. cahooni vs. T. a. brunneicollis) and morphology (i.e. T. a. aedon vs. T. a. parkmanii and T. a. parkmanii vs. T. a. cahooni). Whether variation between sympatric populations represents extremes of a continuum or there is a secondary contact zone between them is still an open question. For instance, vocal divergence in populations with sympatric distribution has been reported in several studies and has often mirrored differences from genetic or playback analyses (e.g., Dingle et al. 2008, 2010, Toews and Irwin 2008, Vázquez-Miranda et al. 2009, SosaLópez et al. 2013). Determining the presence of a secondary contact zone is challenging, particularly in a group like the House Wrens, which exhibit very subtle phenotypic variation that might aid in differentiating multiple forms (e.g., Toews and Irwin 2008). Future 


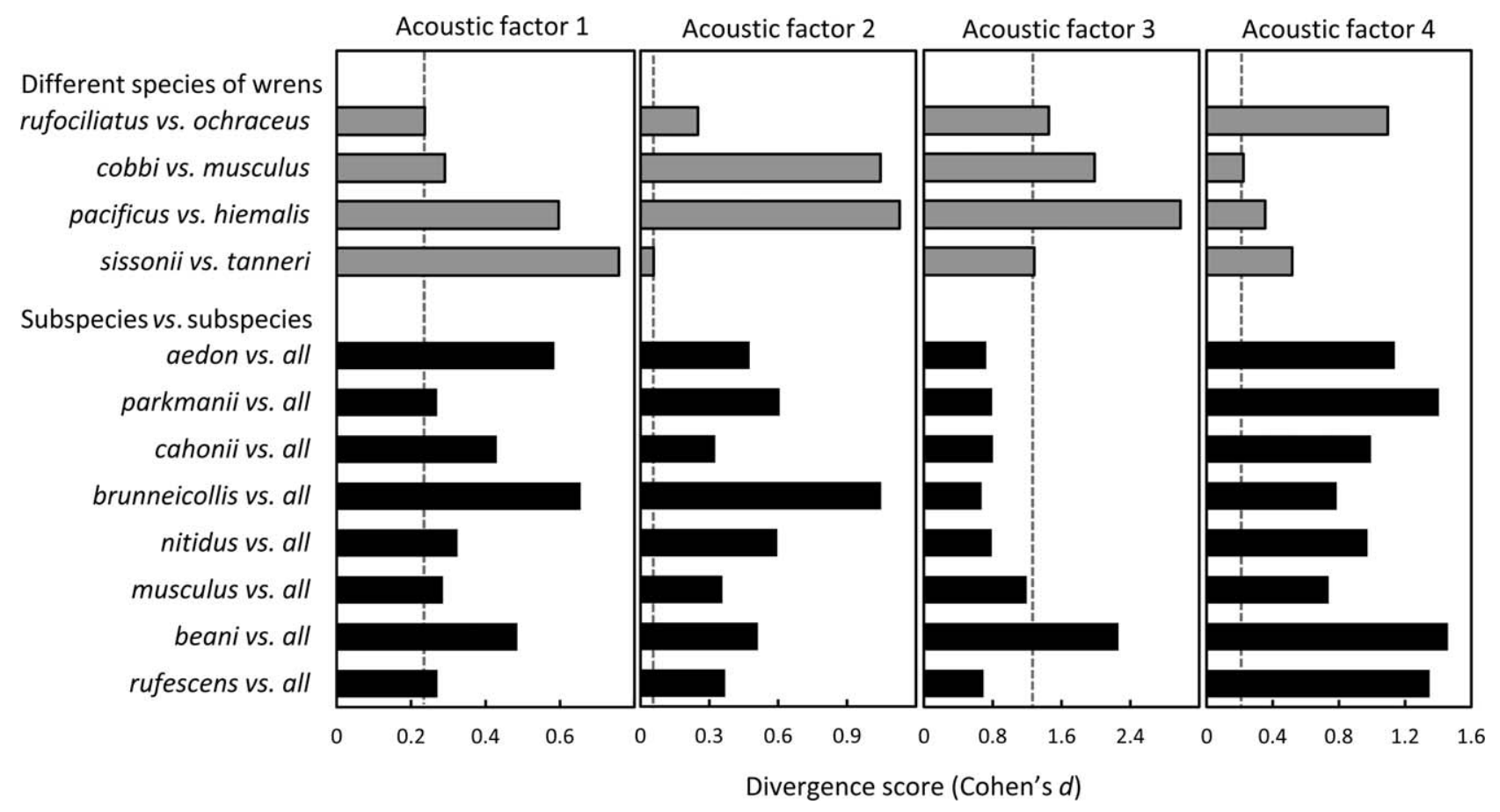

FIGURE 5. Graphs depicting divergence scores between pairs of closely related Troglodytes species (top) and between each subspecies of $T$. aedon and all other subspecies (bottom) for the first four principal component factors describing variation in acoustic features of males. Dashed lines indicate the lowest divergence score between pairs of closely related Troglodytes species. Divergence scores are expressed as the difference in the two groups' means divided by the pooled standard deviations (i.e. Cohen's d).

genetic analyses and playback studies will provide deeper insight into the differences between these taxa in both allopatry and sympatry and the consequences of the acoustic differences with regard to species recognition.

Taxonomically, should some of these bioacoustically divergent groups of House Wrens be considered different species? Our data show that the allopatric subspecies T. $a$. nitidus, T. a. musculus, T. a. beani, and T. a. rufescens can be differentiated from each other acoustically, and from the rest of the subspecies; thus, they may well be treated as different species under the phylogenetic concept (Nixon and Wheeler 1990). On the other hand, the biological species concept requires reproductive isolation between populations for the diagnosis of species (Mayr 1963), and further genetic analysis and playback experiments could help clarify whether complete isolation exists between these taxa. In addition to being acoustically different from one another, we found that the allopatric T. a. nitidus, T. $a$. musculus, T. a. beani, and T. a. rufescens are as different from their counterparts as pairs of recognized Troglodytes species, adding support to the hypothesis that they represent reproductively isolated lineages. Whether sympatric subspecies represent independent evolutionary lineages is still an open question, and further genetic analysis is needed before making a clear taxonomic assessment.
Although we lack genetic data to make a rigorous assessment of taxonomic status, it is relevant that many of these subspecies live in allopatry and that they have distinctive acoustic traits. We do not intend to encourage species definitions based on phenotypic dissimilarity (Moritz and Cicero 2004), but instead we conclude that our data strongly suggest that the current taxonomy underestimates the real diversity within the House Wren complex. We believe that future genetic studies will distinguish some of the currently recognized subspecies as full species. We encourage further taxonomic examination of both island populations and sympatric populations in the House Wren complex.

\section{ACKNOWLEDGMENTS}

For helping us obtain recordings and morphological data, we are deeply indebted to G. Budney and the Macaulay Library; T. Webber and the Florida Museum of Natural History; A. Nelson and the Borror Laboratory of Bioacoustics; L. F. Toledo and Fonoteca Neotropical "Jacques Vielliard"; A. Gordillo, F. Rebón, and Museo de Zoología "Alfonso L. Herrera"; P. Caycedo and the Bancon de Sonidos Animales; F. Gonzalez and the Biblioteca de Sonidos Aves de México; P. Sweet and the American Museum of Natural History; J. Bates, B. Mark, and the Field Museum of Natural History; L. Sandoval; M. Grosselet; M. Araya Salas; R. E. Webster; R. Woods; and T. 
Cellis. We thank the Macaulay Library for loaning us recording equipment. We thank O. Rojas-Soto, A. Gordillo, and J. Martínez-Gómez for logistical assistance and A. Vargas, J. Calderón, E. C. Fernandez-Martínez, and M. Ortiz for field assistance. We thank two anonymous reviewers as well as P. Bitton, B. Graham, L. Sandoval, and D. Wilson for their valuable comments that helped improve the manuscript. We thank InfoNatura for providing the $T$. aedon breeding-range data for Figure 1. For funding, we thank the Consejo Nacional de Ciencia y Tecnología, Secretaría de Educación Publica de México, and the University of Windsor for scholarship support to J.R.S.L., and the AOU and the Field Museum of Natural History for grants to J.R.S.L. We thank the Natural Sciences and Engineering Research Council of Canada, the Canada Foundation for Innovation, and the Government of Ontario for grants to D.J.M.

\section{LITERATURE CITED}

Aleixandre, P., J. H. Montoya, and B. Milá (2013). Speciation on oceanic islands: Rapid adaptive divergence vs. cryptic speciation in a Guadalupe Island songbird (Aves: Junco). PLoS ONE 8(5):e63242.

Alström, P., T. Saitoh, D. Williams, I. Nishiumi, Y. Shigeta, K. Ueda, M. Irestedt, M. Björklund, and U. Olsson (2011). The Arctic Warbler Phylloscopus borealis-Three anciently separated cryptic species revealed. Ibis 153:395-410.

American Ornithologists' Union (1998). Check-list of North American Birds, 7th ed. American Ornithologists' Union, Washington, DC, USA.

Boag, P. T., and P. R. Grant (1984). The classical case of character release: Darwin's finches (Geospiza) on Isla Daphne Major, Galápagos. Biological Journal of the Linnean Society 22:243287.

Brewer, D. (2001). Wrens, Dippers and Thrashers. Yale University Press, New Haven, CT, USA.

Brumfield, R. T. (2012). Inferring the origins of lowland Neotropical birds. The Auk 129:367-376.

Brumfield, R. T., and A. P. Capparella (1996). Genetic differentiation and taxonomy in the House Wren species group. The Condor 98:547-556.

Campagna, L., J. J. H. St Clair, S. C. Lougheed, R. W. Woods, S. Imberti, and P. L. Tubaro (2012). Divergence between passerine populations from the Malvinas-Falkland Islands and their continental counterparts: A comparative phylogeographical study. Biological Journal of the Linnean Society 106:865-879.

Catchpole, C. K., and P. J. B. Slater (2008). Bird Song: Biological Themes and Variations. Cambridge University Press, Cambridge, UK.

Chesser, R. T., R. C. Banks, F. K. Barker, C. Cicero, J. L. Dunn, A. W. Kratter, I. J. Lovette, P. C. Rasmussen, J. V. Remsen, Jr., J. D. Rising, D. F. Stotz, and K. Winker (2012). Fifty-third supplement to the American Ornithologists' Union CheckList of North American Birds. The Auk 129:573-588.

Chesser, R. T., R. C. Banks, F. K. Barker, C. Cicero, J. L. Dunn, A. W. Kratter, I. J. Lovette, P. C. Rasmussen, J. V. Remsen, Jr., J. D. Rising, D. F. Stotz, and K. Winker (2013). Fifty-fourth supplement to the American Ornithologists' Union Check-list of North American Birds. The Auk 130:558-571.
Clements, J. F., T. S. Schulenberg, M. J. Iliff, B. L. Sullivan, C. L. Wood, and D. Roberson (2012). The eBird/Clements checklist of birds of the world, version 6.7. http://www.birds.cornell. edu/clementschecklist/download

Cohen, J. (1992). A power primer. Psychological Bulletin 112: 155-159.

Danner, J. E., R. M. Danner, F. Bonier, P. R. Martin, T. W. Small, and I. T. Moore (2011). Female, but not male, tropical sparrows respond more strongly to the local song dialect: Implications for population divergence. American Naturalist 178:53-63.

de Kort, S. R., and C. ten Cate (2001). Response to interspecific vocalizations is affected by degree of phylogenetic relatedness in Streptopelia doves. Animal Behaviour 61:239-247.

Dingle, C., W. Halfwerk, and H. Slabbekoorn (2008). Habitatdependent song divergence at subspecies level in the Greybreasted Wood-Wren. Journal of Evolutionary Biology 21: 1079-1089.

Dingle, C., J. W. Poelstra, W. Halfwerk, D. M. Brinkhuizen, and H. Slabbekoorn (2010). Asymmetric response patterns to subspecies-specific song differences in allopatry and parapatry in the Gray-breasted Wood-Wren. Evolution 64:35373548.

Gill, F., and D. Donsker (Editors) (2013). IOC World Bird Names, version 3.3. http://www.worldbirdnames.org

González, C., J. F. Ornelas, and C. Gutiérrez-Rodríguez (2011). Selection and geographic isolation influence hummingbird speciation: Genetic, acoustic and morphological divergence in the Wedge-tailed Sabrewing (Campylopterus curvipennis). BMC Evolutionary Biology 11:38.

Hamilton, B. L. (1976). A Monte Carlo test of the robustness of parametric and nonparametric analysis of covariance against unequal regression slopes. Journal of the American Statistical Association 71:864-869.

Holm, S. (1979). A simple sequentially rejective multiple test procedure. Scandinavian Journal of Statistics 6:65-70.

Hosner, P. A., M. B. Robbins, T. Valqui, and A. T. Peterson (2013). A new species of Scytalopus tapaculo (Aves: Passeriformes: Rhinocryptidae) from the Andes of central Peru. The Wilson Journal of Ornithology 125:233-242.

Howell, S. N., and S. Webb (1995). A Guide to the Birds of Mexico and Northern Central America. Oxford University Press, New York, NY, USA.

Johnson, L. S. (1998). House Wren (Troglodytes aedon). In Birds of North America Online (A. Poole, Editor). Cornell Lab of Ornithology, Ithaca, New York, NY, USA. http://bna.birds. cornell.edu/bna/species/380 doi:10.2173/bna.380

Kirschel, A. N., D. T. Blumstein, and T. B. Smith (2009). Character displacement of song and morphology in African tinkerbirds. Proceedings of the National Academy of Sciences USA 106: 8256-8261.

Kroodsma, D. E., and D. Brewer (2005). Family Troglodytidae (wrens). In Handbook of the Birds of the World, vol. 10: Cuckoo-Shrikes to Thrushes (J. del Hoyo, A. Elliott, and D. A. Christie, Eds.). Lynx Edicions, Barcelona, Spain. pp. 356-447.

Lara, C. E., A. M. Cuervo, S. V. Valderrama, D. Calderón-F., and C. D. Cadena (2012). A new species of wren (Troglodytidae: Thryophilus) from the dry Cauca River canyon, northwestern Colombia. The Auk 129:537-550.

Mann, N. I., F. K. Barker, J. A. Graves, K. A. Dingess-Mann, and P. J. B. Slater (2006). Molecular data delineate four genera of 
"Thryothorus" wrens. Molecular Phylogenetics and Evolution 40:750-759.

Martínez Gómez, J. E., B. R. Barber, and A. T. Peterson (2005). Phylogenetic position and generic placement of the Socorro Wren (Thryomanes sissonii). The Auk 122:50-56.

Mayr, E. (1963). Animal Speciation and Evolution. Belknap Press, Cambridge, MA, USA.

McCormack, J. E., and T. B. Smith (2008). Niche expansion leads to small-scale adaptive divergence along an elevation gradient in a medium-sized passerine bird. Proceedings of the Royal Society of London, Series B 275:2155-2164.

Milá, B., B. H. Warren, P. Heeb, and C. Thébaud (2010). The geographic scale of diversification on islands: Genetic and morphological divergence at a very small spatial scale in the Mascarene Grey White-eye (Aves: Zosterops borbonicus). BMC Evolutionary Biology 10:158.

Milá, B., E. S. Tavares, A. M. Saldaña, J. Karubian, T. B. Smith, and A. J. Baker (2012). A trans-Amazonian screening of mtDNA reveals deep intraspecific divergence in forest birds and suggests a vast underestimation of species diversity. PloS ONE 7(7):e40541.

Moritz, C., and C. Cicero (2004). DNA barcoding: Promise and pitfalls. PLoS Biology 2(10):e354.

Navarro-Sigüenza, A. G., and A. T. Peterson (2004). An alternative species taxonomy of the birds of Mexico. Biota Neotropica 4: $1-32$.

Nixon, K. C., and Q. D. Wheeler (1990). An amplification of the phylogenetic species concept. Cladistics 6:211-223.

Nyári, Á. S. (2007). Phylogeographic patterns, molecular and vocal differentiation, and species limits in Schiffornis turdina (Aves). Molecular Phylogenetics and Evolution 44:154-164.

Pyle, P. (1997). Identification Guide to North American Birds, part 1: Columbidae to Ploceidae. Slate Creek Press, Bolinas, CA, USA.

Quinn, G. P., and M. J. Keough (2002). Experimental Design and Data Analysis for Biologists. Cambridge University Press, Cambridge, UK.
Remsen, J. V., Jr., C. D. Cadena, A. Jaramillo, M. Nores, J. F. Pacheco, J. Pérez-Emán, M. B. Robbins, F. G. Stiles, D. F. Stotz, and K. J. Zimmer (2013). A classification of the bird species of South America, version: 20. American Ornithologists' Union. http://www.museum.lsu.edu/ Remsen/SACCBaseline.html

Rice, N. H., A. T. Peterson, and G. Escalona-Segura (1999). Phylogenetic patterns in montane Troglodytes wrens. The Condor 101:446-451.

Rice, W. R. (1989). Analyzing tables of statistical tests. Evolution 43:223-225.

Scott, S. N., S. M. Clegg, S. P. Blomberg, J. Kikkawa, and I. P. F. Owens (2003). Morphological shifts in island-dwelling birds: The roles of generalist foraging and niche expansion. Evolution 57:2147-2156.

Seeholzer, G. F., B. M. Winger, M. G. Harvey, D. Cáceres A., and J. D. Weckstein (2012). A new species of barbet (Capitonidae: Capito) from the Cerros del Sira, Ucayali, Peru. The Auk 129: 551-559.

Sosa-López, J. R., D. J. Mennill, and A. G. Navarro-Sigüenza (2013). Geographic variation and the evolution of song in Mesoamerican Rufous-naped Wrens Campylorhynchus rufinucha. Journal of Avian Biology 44:27-38.

Toews, D. P. L., and D. E. Irwin (2008). Cryptic speciation in a Holarctic passerine revealed by genetic and bioacoustic analyses. Molecular Ecology 17:2691-2705.

Vázquez-Miranda, H., A. G. Navarro-Sigüenza, and K. E. Omland (2009). Phylogeography of the Rufous-naped Wren (Campylorhynchus rufinucha): Speciation and hybridization in Mesoamerica. The Auk 126:765-778.

Wilkins, M. R., N. Seddon, and R. J. Safran (2013). Evolutionary divergence in acoustic signals: Causes and consequences. Trends in Ecology \& Evolution 28:156-166.

Wilson, E. O. (2003). The encyclopedia of life. Trends in Ecology \& Evolution 18:77-80.

Woods, R. W. (1993). Cobb's Wren Troglodytes (aedon) cobbi of the Falkland Islands. Bulletin of the British Ornithologists' Club 113:195-207. 